\title{
Opioid therapy for refractory dyspnea in patients with advanced chronic obstructive pulmonary disease: patients' experiences and outcomes
}

\author{
Graeme M. Rocker MHSc DM, A. Catherine Simpson MA PhD, Joanne Young BHSc, Robert Horton MD, \\ Tasnim Sinuff MD PhD, Jillian Demmons MA, Margaret Donahue MDiv MAHSR, Paul Hernandez MDCM, \\ Darcy Marciniuk MD
}

\section{Abstract}

Background: Dyspnea that is refractory to conventional treatments affects up to $50 \%$ of patients with advanced chronic obstructive pulmonary disease (COPD). Although professional societies recommend opioids in this setting, evidence supporting their use over months is limited. We conducted a multicentre mixed-methods study to understand patients' experiences when opioids are added to optimized conventional treatments for advanced COPD.

Methods: A total of 44 patients (median age 74, range 51-89 years) agreed to participate in this 6-month study. After baseline assessments, immediate-release morphine sulfate syrup (initially $0.5 \mathrm{mg}$ twice daily) was slowly titrated upward based on weekly assessments of symptoms. We conducted semistructured interviews and collected contemporaneous measures of health-related quality of life, severity of dyspnea, anxiety, depression, global ratings of opioid "helpfulness" and adverse effects before, at 2 months and at 4-6 months after opioids were started.

Results: Of the 44 patients, 32 (73\%) completed the trial; 27 (90\%) of 30 patients reported the opioid treatment as very (43\%) or somewhat (47\%) helpful. Three main themes emerged from the patients' overall positive experiences: small gains have big impact; realign hopes with reality; and "try it." Significant improvements were observed in median (interquartile range) scores between baseline and 4-6 months' assessment for health-related quality of life (Chronic Respiratory Questionnaire: 3.5 [2.8-4.0] v. 4.2 [3.6-4.8]; and Chronic Respiratory Questionnaire-Dyspnea domain: 2.8 [2.3-3.6] v. 3.9 [2.8-4.5]) and decreases in severity of dyspnea (numerical rating scale: 7.0 [5.0-8.0] v. 5.0 [4.0-6.0]). Adverse effects were minimal for most patients.

Interpretation: Opioids were a helpful and acceptable intervention for refractory dyspnea in patients with advanced COPD. Many of the patients experienced sustained benefits over months, which supports recent recommendations to consider opioids in this setting. Trial registration: ClinicalTrial.gov, no. NCT00982891

hronic obstructive pulmonary disease (COPD) will be the third leading cause of death globally by 2020. ${ }^{1}$ Recent Canadian data suggest that about 1 in 4 adults 35 years or older can expect to develop COPD. ${ }^{2}$ Dyspnea is the predominant symptom, and up to $50 \%$ of patients with advanced COPD have dyspnea (persistent, episodic or both) that is refractory to conventional treatment. ${ }^{3}$ Dyspnea "crises" often trigger intense feelings of helplessness that can overwhelm patients' and caregivers' abilities to cope. ${ }^{4}$

More than 20 years have passed since morphine was found to be associated with a reduction in dyspnea in patients with COPD. ${ }^{5}$ Despite the systematic review of a decade ago, ${ }^{6}$ experience with using opioids in this clinical context remains limited. Subsequent evidence focuses on, or extrapolates from, short-term effects over hours ${ }^{7,8}$ or days. ${ }^{9}$ Longer-term clinical use over months has received relatively little attention or support until recently. ${ }^{10,11}$ The dearth of quality evidence relating to the longer-term effects of opioids prompted our study.

Building on our previous research in this area, ${ }^{12,13}$ we designed a multicentre mixed-methods study (a) to understand further the experiences of patients living with advanced

Competing interests: Available at the end of the article.

This article has been peer reviewed.

Correspondence to: Graeme Rocker, Graeme.rocker@dal.ca

CMAJ Open 2013.DOI:10.9778/cmajo.20120031 
COPD and refractory dyspnea for which opioids were added to optimized conventional treatments; (b) to explore the longer-term effect (over 4-6 months) of opioid therapy on health-related quality of life, dyspnea, anxiety and depression; and (c) to determine why patients chose to continue or stop using opioids.

\section{Methods}

\section{Study setting and design}

This prospective, longitudinal, observational, interventional study was conducted in both urban and rural settings in the provinces of Nova Scotia, New Brunswick and Saskatchewan. The study had parallel qualitative and quantitative design features. It was approved by Health Canada and received approval from the research ethics boards at each study site (Capital District Health Authority, Halifax, NS; Horizon Health Network, Saint John, NB; and University of Saskatchewan, Saskatoon, Sask.).

\section{Sample size and recruitment}

To address our quantitative outcomes, we considered a conventional potential placebo effect of $30 \%$ and a conservative projected response rate of $50 \%$. We concluded that $30-45$ patients would enable us to meet both quantitative and qualitative study objectives with $80 \%$ power and an $\alpha$ level of 0.05 . Potential participants were patients with a confirmed diagnosis of advanced COPD (Medical Research Council [MRC] dyspnea score of 4 or 5) who had refractory dyspnea despite optimal conventional treatment (defined by 2008 COPD guidelines from the Canadian Thoracic Society ${ }^{14}$ ). We excluded patients with documented overlap syndromes (additional obstructive sleep apnea or hypoventilation). For a complete list of study inclusion and exclusion criteria, see Appendix 1 (available at www.cmajopen.ca/content/1/1/E27/suppl /DC1). For patients with an exacerbation of COPD, we delayed the start of opioids (for at least 4 weeks) until they felt they were back to their baseline. Patients' primary clinicians referred potential and interested participants $(n=63)$ to the study research coordinator, who provided additional study details by telephone or in writing. Consent forms were mailed to some participants to review in advance, although most preferred to have the study coordinator review documentation in person. During initial visits, eligibility was confirmed for 55 of the 63 patients, and study investigators proceeded to address fears and concerns (e.g., about opioid doses and dose increases). At this stage, 8 patients declined to participate (Figure 1; see Appendix 2 for details of attrition, available at www.cmajopen.ca/content/1/1/E27/suppl/DC1).

\section{Qualitative component}

The entire sample was included in the qualitative component, which focused on the participants' experience of (a) living with refractory dyspnea despite taking optimized conventional COPD treatment and (b) having low-dose opioids added to this treatment regimen. This ensured rich data to enhance our insight into, and confidence in, the study's quantitative results.

\section{Intervention}

As in any clinical encounter, local investigators prescribing the opioids assessed potential benefits and harms (e.g., lower doses for patients with renal impairment or low body mass index).

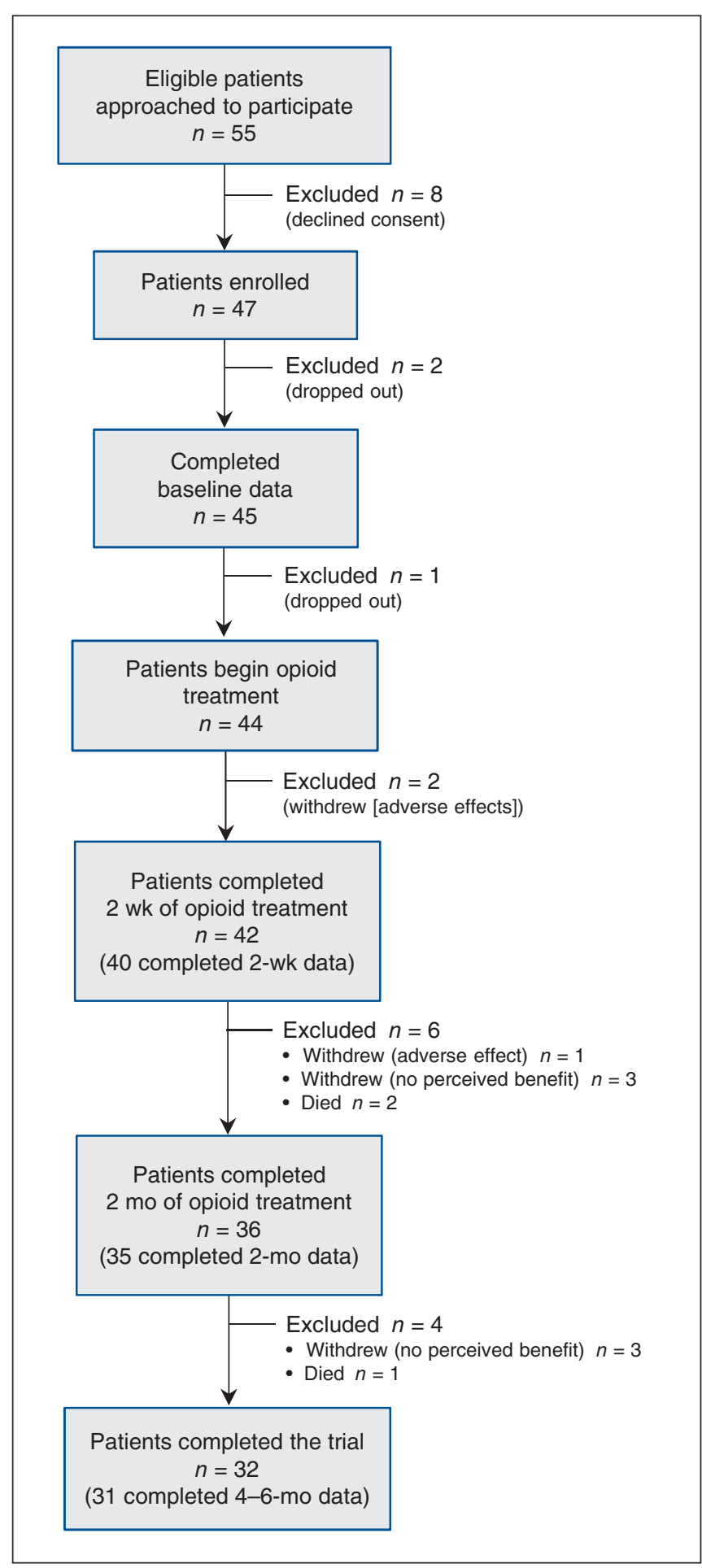

Figure 1: Flow of patients through the trial. Overall, 12 patients did not complete the trial ( 9 dropped out; 3 died); none of the deaths was unexpected or attributed to the use of opioids. (See Appendix 2 for details of attrition, available at www.cmajopen.ca/content/1/1/E27 /suppl/DC1) 
Unless contraindicated, opioid therapy with an immediaterelease morphine sulfate syrup was started (see schedule in Table 1). We intentionally chose a low starting dose and wide dosing interval for the first days of treatment to minimize the likelihood of early opioid-related adverse effects that might decrease adherence. We chose this approach to help gain patients' trust, which was important to justify a slight delay of any therapeutic effect. Because patients were most likely to experience dyspnea when most active (during waking hours), we gradually shortened the dosing interval to every 4 hours and indicated "while awake" on prescriptions for an initial 2week supply of morphine syrup, aiming to provide adequate levels of opioid for 16 of 24 hours.

The patients were given a diary to record opioid doses and frequency, and to $\log$ reasons for missed doses, extra daytime or nocturnal doses as needed, and any adverse effects. As a secondary check on adherence, we asked patients to have study medication available during investigators' visits for assessments. We provided the patients, their family caregivers and family practitioners (for interest) a copy of our opioid titration guide (Table 1) and monitored patients closely through telephone contact during the first 2 weeks of therapy. At each phone contact, patients were asked to rate the "tolerability" of their dyspnea on a 5 -point Likert scale $(1=$ completely tolerable, $5=$ completely intolerable). For those wishing to continue with the trial, opioids were titrated upward gradually as required to achieve tolerable levels of dyspnea.

Opioids were started slowly over week 1 , and dose stabilization occurred at weekly intervals and as per our previous recommendations. ${ }^{15}$ Once a stable effective dose was established, most patients transitioned to a daily or twice-daily sustained-release preparation, according to patterns of dyspnea, with additional immediate-release preparations for episodic dyspnea. If reported adverse effects exceeded benefit, doses were reduced, alternative opioids were considered, or opioids were weaned or stopped. We provided written advice regarding the use of stool softeners and stimulant laxatives to prevent and treat opioid-induced constipation (Appendix 3, avail- able at www.cmajopen.ca/content/1/1/E27/suppl/DC1). For patients with persistent or intolerable adverse effects, an equipotent dose of hydromorphone was offered with no change in dosing interval.

\section{Data collection}

After obtaining informed consent, we collected data on demographic characteristics and functional status ${ }^{16}$ (Appendix 4, available at www.cmajopen.ca/content/1/1/E27/suppl/DC1) and conducted semistructured one-on-one interviews with all participants. Research assistants with experience in qualitative interviewing explored participants' experiences of living with COPD and refractory dyspnea and their attitudes toward opioid use. Interview guides (Appendix 5, available at www.cmajopen.ca /content/1/1/E27/suppl/DC1) were developed through an iterative process based on themes identified in our previous research, literature reviews conducted in preparation for these studies, and testing of the interview guide in pilot studies. ${ }^{12,13}$ Prompts were rarely needed, because study participants readily discussed their experiences and concerns.

Patients completed validated quantitative assessments of their health-related quality of life (Chronic Respiratory Questionnaire $^{17}$ and the McGill Quality of Life Questionnaire $\left.{ }^{18}\right)$; severity of dyspnea (numerical rating scale and Chronic Respiratory Questionnaire-Dyspnea domain); ${ }^{17,19}$ anxiety and depression (Hospital Anxiety and Depression Scale ${ }^{20}$ ); and adverse effects (Numerical Opioid Side Effect assessment tool ${ }^{21}$ ). They completed these assessments at baseline, and during opioid treatment at 2 weeks (except for the Hospital Anxiety and Depression Scale and the McGill Quality of Life Questionnaire), 2 months and 4-6 months (Appendix 6, available at www.cmajopen.ca/content/1/1/E27/supp1/DC1). In addition, they rated the global "helpfulness" of opioids on a 5-point Likert scale ( $1=$ not helpful at all, $5=$ very helpful); whether, when balancing benefits and adverse effects, they wanted to continue opioid therapy (Yes or No); and the reasons for their choice in terms of changes in dyspnea, quality of life and adverse effects. ${ }^{21}$ Patients completed quantitative assessments after their qualita-

\section{Table 1: Opioid dosing and titration schedule}

\begin{tabular}{|c|c|c|}
\hline Timetable & Drug and dosage & Dyspnea outcome measure \\
\hline \multicolumn{2}{|l|}{ Week 1} & \multirow{4}{*}{$\begin{array}{l}\text { At end of week } 1 \text {, if dyspnea score on Likert scale } \geq 4 \\
\text { (i.e., dyspnea is somewhat intolerable or completely } \\
\text { intolerable), then: }\end{array}$} \\
\hline Day 1,2 & Morphine sulfate $0.5 \mathrm{mg}$ twice daily & \\
\hline Day 3, 4 & Morphine sulfate $0.5 \mathrm{mg}$ every 4 hours & \\
\hline Day $5,6,7$ & Morphine sulfate $1 \mathrm{mg}$ every 4 hours & \\
\hline Week 2 & Morphine sulfate 2 mg every 4 hours & At end of week, if dyspnea score $\geq 4$ as above, then: \\
\hline Week 3 & Morphine sulfate $3 \mathrm{mg}$ every 4 hours & At end of week, if dyspnea score $\geq 4$ as above, then: \\
\hline Week 4 & Morphine sulfate 5 mg every 4 hours & At end of week, if dyspnea score $\geq 4$ as above, then: \\
\hline Week 5+ & \multicolumn{2}{|c|}{$\begin{array}{l}\text { Ongoing titration weekly, with increase of } 30 \%-50 \% \text { in dose based on severity of dyspnea and } \\
\text { adverse effects. If persistent intolerable adverse effects develop, revert to previous tolerated dose } \\
\text { and re-evaluate in } 48 \text { hours. If adverse effects persist, rotate to hydromorphone or taper dose by } \\
50 \% \text { per day and stop over } 72 \text { hours. }\end{array}$} \\
\hline Week 6+ & \multicolumn{2}{|c|}{$\begin{array}{l}\text { Patients who remain on a stable dose of opioid (i.e., have not required titration in the preceding } \\
2 \text { weeks) can switch to a sustained-release preparation. }\end{array}$} \\
\hline
\end{tabular}


tive interviews; if fatigued, they completed and returned them to the study coordinator within a few days.

\section{Analysis}

We used medians and interquartile ranges (IQRs) to describe continuous data at single assessment points, and the sign test to assess the significance of differences between scores at baseline and at 4-6 months. To be conservative in our analysis of effects, we used nonparametric analysis throughout.

Following verbatim transcription of digital audio recordings of the interviews, the research assistants analyzed the data using "interpretive description," ${ }^{22}$ an approach we have described elsewhere. ${ }^{12}$ After describing patients' experiences with opioids, and through a process of thematic coding and analysis, we interpreted possible meanings from a clinical perspective. We used NVivo 7 and ATLAS.ti software programs for data management.

\section{Results}

Between March 2010 and November 2011, 47 (85\%) of 55 eligible patients were enrolled, of whom 45 (26 women, 19 men) provided baseline data (Figure 1); the median age was 74 (range 51-89) years. At enrolment, most of the 45 patients $(37$ [82\%]) had an MRC dyspnea score of 5 (i.e., they were too short of breath to leave their homes or breathless when dressing or undressing). The remaining 8 patients (18\%) had an MRC score of 4 but met additional enrolment criteria indicating severe disease (see Appendix 1). Additional demographic data are presented in Table 2 .

Of the 45 patients who provided baseline data, 44 began opioid treatment in addition to conventional treatment; 32 (73\%) of the 44 completed the study (Figure 1; Appendix 2).

\section{Table 2: Baseline demographic data}

\begin{tabular}{|c|c|}
\hline Characteristic & $\begin{array}{c}\text { No. (\%) of patients } \\
n=45^{\star}\end{array}$ \\
\hline \multicolumn{2}{|l|}{ Sex } \\
\hline Female & $26(58)$ \\
\hline Male & $19(42)$ \\
\hline Age, yr, median (range) & $74(51-89)$ \\
\hline \multicolumn{2}{|l|}{ Location } \\
\hline Nova Scotia & $31(69)$ \\
\hline New Brunswick & $8(18)$ \\
\hline Saskatchewan & $6(13)$ \\
\hline \multicolumn{2}{|l|}{ Dyspnea severity } \\
\hline MRC 5 & $37(82)$ \\
\hline MRC 4 & $8(18)$ \\
\hline $\mathrm{FEV}_{1}, \%$ of predicted, mean $\pm \mathrm{SD}(n=34)$ & $26.8(8.9)$ \\
\hline Long-term oxygen use & $27(60)$ \\
\hline High school education or less & $25(58)$ \\
\hline $\begin{array}{l}\text { Note: MRC = Medical Research Council dyspnea sca } \\
\text { volume in the first second, } \mathrm{SD}=\text { standard deviation. } \\
\text { *Unless stated otherwise. }\end{array}$ & $\mathrm{FEV}_{1}=$ forced expiratory \\
\hline
\end{tabular}

Of the 32 patients, 20 were taking a sustained-release preparation as their primary opioid at the end of the study period $(10 \mathrm{mg} / \mathrm{d}, n=12$ [38\%]; $15 \mathrm{mg} / \mathrm{d}, n=7$ [22\%]; or $20 \mathrm{mg} / \mathrm{d}$, $n=1[3 \%])$. Of the other patients, $9(28 \%)$ were still taking immediate-release morphine syrup (average daily dose $5.4 \mathrm{mg})$, and 3 (9\%) had switched to hydromorphone syrup. The daily total morphine equivalent dose (mean \pm standard deviation) was $4.6 \pm 1.5 \mathrm{mg}$ at 2 weeks, $8.1 \pm 3.9 \mathrm{mg}$ at 2 months and $10.2 \pm 4.3 \mathrm{mg}$ at $4-6$ months.

\section{Experiences and attitudes toward opioids}

Most of the patients who completed the study described their experience with the opioid therapy as positive in terms of overall perceived benefit (Box 1). We identified 3 main themes within their positive perception of the experience: small gains have big impact; hope versus reality; and "try it!"

\section{Small gains have big impact}

Baseline interviews indicated participants' desire to live as well as possible for as long as possible, but also their modest hopes in this regard. Their expectations indicated a sense of resignation, resilience and hope for small improvements or slowed deterioration. During the period of opioid therapy, small gains in relation to shortness of breath and accompanying anxiety substantially affected quality of life in terms of improved activity level, mood, relationships and independence. Such

\section{Box 1: Positive experience}

- It helped me and I have no side effects that I know of from it. So it didn't do me any harm and ... [it helped] me more than it hindered me, 'cause as far as trying to think of anything it did negative, I can't. There's nothing negative there at all, and everything that helped me I think it was positive from that. Because since I started taking that, I felt way better. [NS25-3]

- I'm feeling $100 \%$ better than I did before. And anybody they want to give that to, they should give it to them, anybody that wants to take it, should take it, 'cause it is good. [NS010-3]

- I think you guys have done wonderful things for this old fella. Thank you for going to the trouble of maybe at least giving him a little better quality. [NB02-3]

\section{Box 2: Small gains have big impact}

- It seems that I'm always climbing up hill, and I get sort of tired of climbing up that hill or trying to get out of that barrel or whatever l'm in ... It's maybe hard for somebody that isn't the way I am to understand or feel ... you're grasping for any little thing that comes along, and this morphine I guess it's been the best little thing that l've grasped for, for quite a while and even that little bit of help is a little bit of help, not down but rather up. [SK02-2]

- ... It's made quite a difference for me. I wish I had heard about it sooner. It makes doing my chores a little more bearable, and you know at this stage for me it's all about quality of life and if I don't have much quality of life, then what's the point of being here. So I think the morphine helps me to be able to enjoy things like, even taking a bath, I still enjoy my bath. And I can walk a little bit further without having to rest. You put those little things all together and it's a big thing, right? [NS024-3] 
changes were welcomed as minor miracles in the face of what was felt to be an inexorable progression of illness - "small gains have big impact" (Box 2).

Tangible improvements: Individually, patients referred to varying types and degrees of improvement that contributed to better quality of life (Box 3). The most common improvements related to breathing (less of a struggle, shortness of breath less severe, less need for rescue medication), activity and mobility (quicker recovery, improved mobility), and anxiety (calmer, less anxious and fearful). Some patients noticed improvements in mood (less irritable, more positive outlook), depression, hope, relationships with family or friends, and sleep. Many noted fewer visits to their doctor and the emergency department. Several felt opioids had extended their lives, and one said it had helped avoid long-term care.

Less tangible benefits: Besides small gains in quality of life, many participants appreciated the support they received from, and the trust they developed in, the study team (Box 4).

\section{Box 3: Tangible improvements}

\section{Breathing}

- My breathing has changed a bit, not $100 \%$ but it's suitable for me that I get around better. And as long as I stay on the right hours, if I miss one [dose], an hour later or something you can tell the difference ... Otherwise it's been good for my breathing [NSO30-2]

- Probably the best thing l've noticed it [morphine] has changed is when I get short of breath I'm not gasping as much as I used to. [SK05-3]

\section{Activity/mobility}

- I've been cleaning out the kitchen, cleaning out the cupboards and things like that, take my time ... but l've noticed a big difference in things like that. [NB01-3]

- Well I move around easier. I find that I'm more hopeful, I have a drive to get out of bed and do things and I seem to have more energy to do things. [NS24-3]

\section{Independence}

- I can do more things without getting breathless, like more things for myself rather than depending on [spouse] all the time. That's a big thing for me. [SK04-2]

\section{Mood/relationships}

- I've noticed that I don't get quite so uptight ... as I used to, I don't like to nag, to me it's being negative, and I find now that I can respond where it's not instant fury or instant feeling sorry for myself. I still get that way to a certain point sometimes, depending on what's happening, what's being said but ... so it's keeping me calmer I guess, or on a more even keel. [SK04-2]

\section{Perceptions of life expectancy, physician visits} and symptoms

- Ah, they [fears] may have improved some ... since it's a terminal illness that I have, maybe we put the termination date off into the future somewhat. And we've extended my life. [NB06-3]

- My breathing has gotten a lot easier when I take morphine, whereas before I was using my aerosols like 3 or 4 times a day and going down to [the emergency department] 2 or 3 times a week usually because of poor breathing, and I haven't had that since l've been on the morphine. [NS010-3]

\section{Realign hopes with reality}

Despite early positive assessment and modest hopes, the opioid experience necessitated ongoing realignment of feelings for most patients, since benefits and burdens ebbed and flowed.

Disappointment: Early improvement (for many) was followed by a plateau or diminution in effectiveness for some, which engendered disappointment and concern (Box 5). A few experienced inconsistent effectiveness, which left them unsure about whether or not to continue with an opioid. A small number reported insufficient or no improvement along with a burden of adverse effects or dosing difficulties, which left them disappointed and sad.

Negative experiences: For the few patients who rated the opioid trial as negative or neutral overall, the negative aspects of adverse effects and opioid dosing outweighed any impact on symptoms or quality of life and resulted in an experience that involved more burden than benefit (Box 6).

Gastrointestinal symptoms, primarily constipation, were the most frequent and troubling adverse effects reported. A few patients reported nausea, vomiting, bloating, cramping and loss of appetite, most of which resolved over time and as constipation was better controlled. Other adverse effects

\section{Box 4: Support and trust}

- No I can't think that you people could have done any more than you have for me. You know you were right there, [study RRT] was always there at the end of the phone if we needed her. [NB01-3]

- It's perfect as far as the staff ... the staff have been very helpful. I've got the calling card right here for [study RRT], any time I want her. [NB02-3]

Note: RRT = registered respiratory therapist.

\section{Box 5: Disappointment}

- The shortness of breath got better for a while but then it went right back to what it was before I started taking the morphine ... It gradually got better from the time I started up until about 3 weeks ago. [NS001-3]

- I am kind of disappointed. I thought maybe it would be better for that trip. But it was about the same as the pre-morphine period. [NS28-2]

- So ah, all in all I didn't feel that I was getting anything from it, so it was just another burden. I was so hopeful. [NSO02-3]

\section{Box 6: Negative experience}

- I couldn't feel anything at all in the line of difference ... yeah it was another burden sort of thing .... between the time elements and the constipation. [NS002-3]

- When I first started taking the morphine I had a lot of stomach problems as well, I had an enormous amount of gas and upset stomach and queasiness and so on ... that disappeared but was replaced with the constipation problem. [NB004-2]

- The liquid is a pain to take, especially if you're out or something. This way [long-acting form] if you're going out I throw a tablet or a capsule in my pocket and I pop it. [SKO02-3] 
included sleepiness, itching, dry mouth, sweating, dizziness and skin changes, but the experience of one patient accounted for most of these.

Patients reported difficulties with the short-acting syrup, including taste, messiness and problems with drawing up a dose, frequency of dosing, and transporting and taking the syrup when away from home (Box 6). Most of those who commented on the dosing preferred the longeracting daily pill.

Hopefulness and fears: The number of participants choosing to continue opioids was seen as a sign of a positive experience and ongoing hopefulness. Early uncertainties concerned addiction, sedation, and associations with end of life, cancer and pain; later uncertainties dealt with dose changes, dose effects and opportunity to continue (Box 7).

\section{"Try it!"}

Regardless of their overall assessment of the experience, most appreciated the chance to try opioids (Box 8). Overwhelmingly, their advice to others was "try it, you have nothing to lose," even though there were no guarantees of effectiveness. Most seemed to feel that, at their stage of illness, any option that might improve quality of life, even marginally and for a short time, was worth a try. Having completed the trial, they were more confident than ever of this advice, even those for whom the experience was less positive.

In summary, for most participants who completed the study, the experience was positive in terms of "small gains have big impact." Disappointment owing to negative adverse effects, dosing difficulties, and waning, inconsistent or inadequate effectiveness necessitated a realignment of expecta-

\section{Box 7: Hopefulness and fears}

- I'm not as afraid of it as I was. You know I was afraid because you hear "morphine" and you think "addiction." [SK004-2]

- Well at first I thought it [morphine] was just at the end of life and I didn't want to start it because I thought I didn't need it for, you know, for the end of life. [NS07-1]

- It [experience taking opioids] has improved since and I noticed a difference without it ... it's possible to continue with the morphine after the study is done, I think I would like to go with that. [SK04-2]

\section{Box 8: "Try it!"}

- Do it. Just do it. Just do it, if you've got COPD do it. Dare to try. I don't know, maybe it doesn't work for everybody, but you don't know unless you try it, right. I know it worked for me and I'm glad I tried it. [NS24-3]

- Anything is better than nothing when it comes to breathing. [NS28-2]

- I've realized a long time ago, I'm not going to get better. In fact, it's going to be the other way around, so for people that are in my position ... if taking morphine helps you just that little bit you know, so that it gives you a positive attitude or positive little bit, l'd say hey go for it. [SK002-2] tions for some despite their initial modest hopes. For a few, the gains were not sufficient to outweigh these negatives, which resulted in an overall negative or neutral assessment of their opioid experience. Despite this, most of the participants appreciated the opportunity to "try it" and strongly endorsed others with this illness to do likewise, the implication being "you have nothing to lose but potentially something good to gain."

\section{Quantitative data}

At 4-6 months, 27 (61\%) of the 44 participants in the original cohort who took an opioid for refractory dyspnea (and $90 \%$ of the 30 patients at trial completion) reported that they found it helpful. The proportions of patients finding their opioid therapy helpful (or not) at 2 weeks, 2 months and 4-6 months are shown in Figure 2.

Quantitative measures support the qualitative findings (Table 3). Early improvements in dyspnea intensity (as shown by both measures) and in health-related quality of life (as shown by the Chronic Respiratory Questionnaire) were maintained through the next months (Table 3). The improvement in a more global measure of quality of life (the McGill Quality of Life Questionnaire) was of borderline significance.

Adverse effects: Of 10 key adverse effects, 9 did not change from baseline to 6 months (Table 4). Scores for dry mouth fell. There were no issues of adherence or abuse, and no prescriptions needed to be filled ahead of schedule.

The study participants in Nova Scotia and New Brunswick who reached 2 months $(n=32)$ and then 4-6 months $(n=29)$ provided responses regarding choices (and strength of choices) to continue (or not) with opioids in terms of relief from dyspnea or improvements in quality of life, or both (these data were not captured in Saskatchewan). We summarize these data in Table 5. These choices were informed by patients' assessments of the opioid benefits and adverse effects balance as summarized in Table 6 .

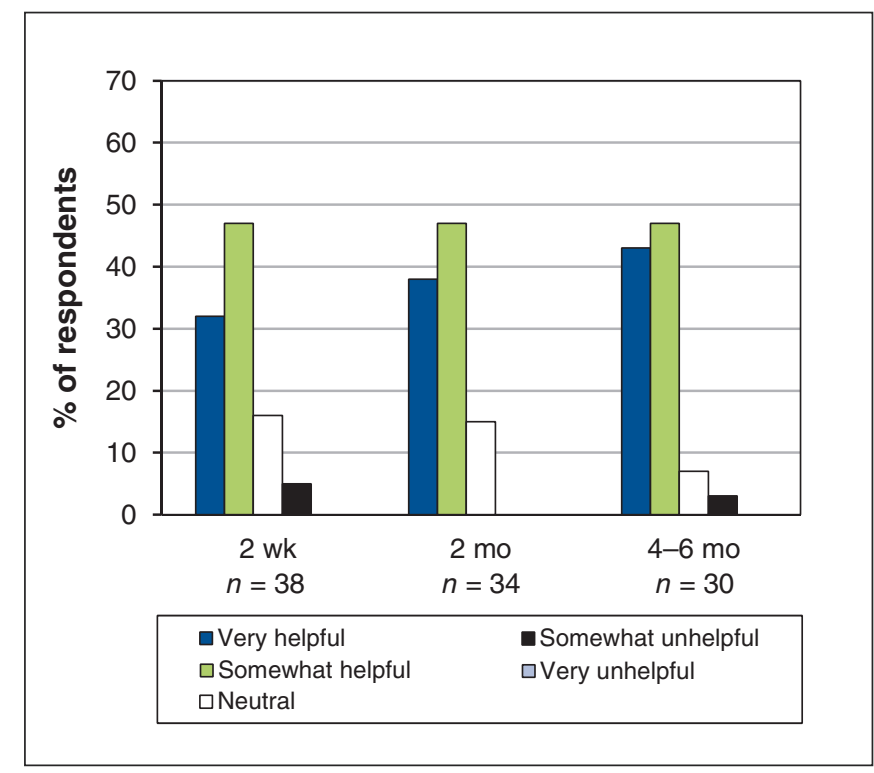

Figure 2: Global ratings of "helpfulness" of opioids on 5-point Likert scale. 


\section{Clinical issues}

The mortality rate of 7\% (3/44) was lower than expected given the participants' disease severity and projections from other studies. ${ }^{23}$ Beyond the 2 "terminal" admissions (Appendix 2), the remaining 17 admissions ( $n=11$ patients, duration 3-17 days) ran expected clinical courses (early noninvasive ventilation with bilevel positive airway pressure for some, as in admissions predating opioids). Mostly, opioid doses were unchanged, in a few instances were weaned slightly for a few days, or in 2 instances were increased. All patients were discharged with preadmission doses.

\section{Interpretation}

Treatment with opioids was helpful for $61 \%$ of patients with advanced COPD whose dyspnea was refractory to conventional therapy. Beneficial effects were achieved early and, for most patients, were sustained over several months. Some improvements in quality of life were dramatic, and in general, patients indicated that small gains had a big impact on breathing, activity levels and mood. Some realignment of expectations was still necessary, and there was a palpable disappointment for the few participants who perceived no benefit. For

Table 3: Changes in quantitative measures from baseline to 6 months

\begin{tabular}{|c|c|c|c|c|c|c|}
\hline \multirow[b]{2}{*}{ Measure } & \multicolumn{5}{|c|}{ Median (IQR) } & \multirow[b]{2}{*}{$p$ value } \\
\hline & $\begin{array}{c}\text { Baseline } \\
n=45\end{array}$ & $\begin{array}{c}2 \mathrm{wk} \\
n=39\end{array}$ & $\begin{array}{c}2 \mathrm{mo} \\
n=34\end{array}$ & $\begin{array}{c}4-6 \text { mo } \\
n=31\end{array}$ & $\begin{array}{c}\text { Difference between } \\
\text { baseline and 4-6 mo } \\
\qquad n=31\end{array}$ & \\
\hline \multicolumn{7}{|l|}{ Health-related quality of life } \\
\hline CRQ & 3.5 (2.8 to 4.0$)$ & 4.2 (3.8 to 4.7$)$ & 4.1 (3.6 to 4.8 ) & 4.2 (3.6 to 4.8$)$ & $0.6(0.1$ to 1.3$)$ & $<0.001$ \\
\hline $\begin{array}{l}\text { McGill Quality of Life } \\
\text { Questionnaire }\end{array}$ & 5.0 (3.0 to 6.0$)$ & $-^{*}$ & 5.5 (4.0 to 7.5$)$ & 5.0 (5.0 to 7.0$)$ & $1.0(0$ to 2.0$)$ & 0.053 \\
\hline \multicolumn{7}{|l|}{ Dyspnea } \\
\hline Numerical rating scale & 7.0 (5.0 to 8.0$)$ & 5.0 (4.0 to 7.0$)$ & 5.0 (4.0 to 6.0$)$ & $5.0(4.0$ to 6.0$)$ & $-2.0(-3.0$ to 1.0$)$ & 0.02 \\
\hline CRQ-D & 2.8 (2.3 to 3.6$)$ & 3.9 (3.0 to 4.5$)$ & 3.6 (3.0 to 4.2$)$ & 3.9 (2.8 to 4.5$)$ & $0.6(0$ to 1.4$)$ & 0.004 \\
\hline \multicolumn{7}{|l|}{ Anxiety and depression } \\
\hline HADS-Anxiety & $8.0(6.0$ to 10.0$)$ & $--^{*}$ & 7.0 (3.0 to 9.0$)$ & $7.0(4.0$ to 11.0$)$ & $-1.5(-3.0$ to 1.0$)$ & 0.2 \\
\hline HADS-Depression & $8.0(6.0$ to 11.0$)$ & $-{ }^{*}$ & 6.0 (4.0 to 8.0$)$ & 7.0 (5.0 to 9.0$)$ & $-1.0(-3.0$ to 0.0$)$ & 0.08 \\
\hline
\end{tabular}

Table 4: Adverse effects of opioids reported by patients*

\begin{tabular}{|c|c|c|c|c|}
\hline \multirow[b]{2}{*}{ Symptoms } & \multicolumn{4}{|c|}{ NOSE score, ${ }^{\star}$ mean \pm SD $\dagger$} \\
\hline & $\begin{array}{c}\text { Baseline } \\
n=45\end{array}$ & $\begin{array}{c}2 \mathrm{wk} \\
n=39\end{array}$ & $\begin{array}{c}2 \text { mo } \\
n=34\end{array}$ & $\begin{array}{l}4-6 \text { mo } \\
n=31\end{array}$ \\
\hline Nausea/vomiting/lack of appetite & $2.23 \pm 2.89$ & $1.29 \pm 2.13$ & $1.62 \pm 2.69$ & $1.71 \pm 2.24$ \\
\hline $\begin{array}{l}\text { Fatigue/trouble concentrating/hallucinations/ } \\
\text { drowsiness }\end{array}$ & $3.15 \pm 2.83$ & $2.10 \pm 2.73$ & $2.38 \pm 2.62$ & $2.97 \pm 2.56$ \\
\hline Constipation & $2.80 \pm 2.80$ & $2.92 \pm 3.38$ & $3.33 \pm 3.21$ & $3.32 \pm 3.11$ \\
\hline Itching & $2.03 \pm 2.90$ & $1.23 \pm 1.84$ & $1.66 \pm 2.27$ & $1.52 \pm 2.61$ \\
\hline Decreased sexual desire & $4.61 \pm 4.79$ & $2.22 \pm 3.80$ & $2.39 \pm 4.15$ & $3.68 \pm 4.61$ \\
\hline Dry mouth & $5.23 \pm 3.53$ & $3.31 \pm 2.78$ & $4.59 \pm 3.17$ & $4.52 \ddagger \pm 3.08$ \\
\hline Abdominal pain & $2.80 \pm 3.13$ & $1.36 \pm 1.69$ & $1.88 \pm 2.48$ & $1.77 \pm 2.22$ \\
\hline Sweating & $1.58 \pm 2.05$ & $1.36 \pm 1.91$ & $1.33 \pm 1.83$ & $1.42 \pm 1.95$ \\
\hline Headaches/dizziness & $2.08 \pm 2.41$ & $1.95 \pm 2.45$ & $1.76 \pm 2.50$ & $1.84 \pm 2.37$ \\
\hline Urine retention & $1.39 \pm 2.14$ & $1.21 \pm 2.09$ & $1.15 \pm 1.86$ & $1.23 \pm 1.61$ \\
\hline Minimum completion rate for any question, no. (\%) & $36(80)$ & $36(92)$ & $31(91)$ & $28(90)$ \\
\hline \multicolumn{5}{|c|}{$\begin{array}{l}\text { Note: SD = standard deviation. } \\
\text { *Scores for self-reported adverse effects were derived with use of the NOSE (Numerical Opioid Side Effect) assessment tool; }{ }^{21} \text { scores range from } 0 \text { (not present) to } 10 \text { (bad). } \\
\text { †Unless stated otherwise. } \\
\ddagger p<0.05 \text { compared with baseline. }\end{array}$} \\
\hline
\end{tabular}


both health-related quality of life (as shown by the Chronic Respiratory Questionnaire) and dyspnea intensity (as shown by the numerical rating scale and the Dyspnea domain of the Chronic Respiratory Questionnaire), the change at 4-6 months from baseline well exceeded the minimal clinically important difference established for the assessment tools (e.g., 0.5 for the Chronic Respiratory Questionnaire and the numerical rating scale ${ }^{24,25}$ ), which indicated a clear clinical improvement. Perhaps as a consequence of our slow titration schedule, adverse effects were also minimal for most patients, who felt that some adverse effects were an acceptable trade-off for the improvements they experienced in their dyspnea and quality of life.

Two other studies have reported effects of opioids over weeks to months in patients with COPD-related dyspnea. An early 6-week crossover study from New Zealand rapidly moved a cohort of 16 patients with COPD from a starting dose of $10 \mathrm{mg} / \mathrm{d}$ to a potential daily dose of $40 \mathrm{mg}$ of sustained-release morphine at 2 weeks. ${ }^{26}$ There was no change in health-related quality of life (Chronic Respiratory Questionnaire) in the treatment group compared with the placebo group, and almost all of the patients experienced adverse

\begin{tabular}{|c|c|c|}
\hline \multirow[b]{2}{*}{ Statement } & \multicolumn{2}{|c|}{ No. $(\%)$ of responses* } \\
\hline & $\begin{array}{l}2 \mathrm{mo} \\
n=34\end{array}$ & $\begin{array}{c}4-6 \text { months } \\
n=31 \\
\left(41 \text { responses }^{*}\right)\end{array}$ \\
\hline $\begin{array}{l}\text { I would strongly prefer to continue on opioids because they } \\
\text { provide significant relief from dyspnea }\end{array}$ & $8(24)$ & $12(29)$ \\
\hline $\begin{array}{l}\text { I would strongly prefer to continue on opioids because they } \\
\text { provide significant improvement in my quality of life }\end{array}$ & $13(38)$ & $9(22)$ \\
\hline $\begin{array}{l}\text { I would prefer to continue on opioids because they provide } \\
\text { significant relief from dyspnea }\end{array}$ & 1 (3) & $7(17)$ \\
\hline $\begin{array}{l}\text { I would prefer to continue on opioids because they provide } \\
\text { significant improvement in my quality of life }\end{array}$ & $8(24)$ & $10(24)$ \\
\hline $\begin{array}{l}\text { I do not have any feelings or preferences one way or another } \\
\text { for continuing on opioids or not }\end{array}$ & $3(8)$ & $3(7)$ \\
\hline I would prefer to be tapered off opioids & 0 & 0 \\
\hline I would strongly prefer to be tapered off opioids & 1 (3) & 0 \\
\hline
\end{tabular}

Table 6: Balancing benefits and adverse effects of opioids

\begin{tabular}{|lcc|}
\hline & & No. (\%) of responses* \\
\cline { 2 - 3 } & & $\begin{array}{c}4-6 \text { months } \\
n=27\end{array}$ \\
Statement & $\begin{array}{c}2 \text { mo } \\
n=32\end{array}$ & $13(45)$ \\
\hline $\begin{array}{l}\text { Opioids continue to provide significant relief from dyspnea } \\
\text { with minimal side effects }\end{array}$ & $16(50)$ & 2 (7) \\
\hline $\begin{array}{l}\text { Opioids continue to provide significant relief from dyspnea } \\
\text { but with significant side effects }\end{array}$ & 0 & 0 \\
\hline $\begin{array}{l}\text { Opioids continue to provide significant relief from dyspnea } \\
\text { but with side effects that are not tolerable }\end{array}$ & 0 & 10 (34) \\
\hline $\begin{array}{l}\text { Opioids are providing some relief from dyspnea and the side } \\
\text { effects are tolerable }\end{array}$ & $14(44)$ & 0 \\
\hline $\begin{array}{l}\text { Opioids are providing some relief from dyspnea but the side } \\
\text { effects are not tolerable }\end{array}$ & 0 & 0 \\
\hline $\begin{array}{l}\text { Opioids are not providing much relief from dyspnea but the side } \\
\text { effects are tolerable }\end{array}$ & 1 (3) \\
\hline $\begin{array}{l}\text { Opioids are not providing much relief from dyspnea but the side } \\
\text { effects are not tolerable }\end{array}$ & 1 (3) \\
\hline *Some patients provided more than one response. & & \\
\hline
\end{tabular}


effects. Although $25 \%$ of the participants chose to continue with morphine in an open-label phase at 3 months, the authors concluded they would not recommend morphine as a treatment for most patients with severe breathlessness caused by COPD. ${ }^{26}$ More recently, in a dose-increment and pharmacovigilance study in Australia involving 83 patients with refractory dyspnea $\left(n=45\right.$ due to COPD) ${ }^{10}$ sustained-release morphine was started at a dose of $10 \mathrm{mg} / \mathrm{d}$ and was increased to 20 or $30 \mathrm{mg} / \mathrm{d}$ if not effective. No benefit was seen beyond $20 \mathrm{mg} / \mathrm{d}$. There were no instances of respiratory depression during a mean follow-up of 3 months. At 3 months, benefit from opioids had been maintained for $33 \%$ overall, ${ }^{10}$ although it is not possible from reviewing the published data to determine the proportion of patients with COPD (v. others with dyspnea) who found benefit.

Our study builds on previous findings by using a more individualized approach to initiation and titration of a shortacting opioid preparation and evaluating both quantitative and qualitative measures of dyspnea and quality of life over a longer follow-up period in a cohort of patients with refractory dyspnea exclusively due to advanced COPD. Few patients chose to withdraw from our trial, and for 30 patients reporting effects at 4-6 months, $90 \%$ favoured continuing treatment. In contrast to previous studies, our qualitative evaluation provided practical insights into the patient experience of dyspnea that small but statistically significant changes in measurable objective variables cannot provide. In addition, we provide a summary of clinical implications and "lessons learned" in Appendix 7 (available at www.cmajopen.ca/content /1/1/E27/suppl/DC1).

\section{Strengths and limitations}

Our study has a number of strengths. We used mixed methods to understand the complex phenomenon of living with refractory dyspnea of advanced COPD, before and after introducing opioids, consistent with calls for this approach. ${ }^{25}$ We conducted extensive qualitative interviews and administered several questionnaires to provide a comprehensive assessment of this experience and used both unidimensional (numerical rating scale) and multidimensional (Chronic Respiratory Questionnaire) quantitative assessments of dyspnea, as recently recommended..$^{19}$ We assessed participants over months (compared with other studies of shorter durations), strengthening evidence for the safety and efficacy of this treatment option for refractory dyspnea. ${ }^{10}$ Only 9 (20\%) of the 44 patients who began taking opioids withdrew, a remarkably low proportion for any clinical trial given our patients' severity of illness; again, this speaks to the likely efficacy and acceptability of the treatment. We had surprisingly high completion rates $(80 \%-90 \%)$ for our questionnaires. Finally, patients were enrolled, and opioids titrated, based primarily on symptom severity and not on considerations of the presence or absence of chronic respiratory failure (i.e., we did not require or follow arterial blood gas levels). This provides additional confidence that the initiation, titration and maintenance of opioid therapy in patients with advanced respiratory disease can be done safely without invasive monitoring.
Limitations of this study include a potential sampling bias; most patients were enrolled in the primary centre where the principal investigator and team had extensive experience with using opioids for dyspnea in this population. A placebo effect (considered in our sample size calculations) might be related to the medication itself (its apparent effect at low dosage and with minimal adverse effects) or to the level of support, particularly early in the trial (Box 4). However, the extent and duration of benefit, and high study completion rate, support clinical efficacy (see further details in Appendix 8 for rationale, available at www.cmajopen.ca/content/1/1/E27/suppl/DC1). A potential placebo effect could be confirmed or refuted within a well-designed randomized controlled trial (RCT) that could now build upon our findings, with outcomes meaningful to patients. ${ }^{27}$ We felt an RCT to be premature on several grounds at the time of our study, given the extent of the unknown factors related to prescribing opioids for refractory dyspnea (e.g., opioid formulation, optimal initial dosing and titration schedules). ${ }^{15,25}$ The small sample limits the generalizability of our findings; however, generalizability to all patients with advanced COPD was not our intent, as per our individualized pharmacotherapeutic approach.

\section{Conclusion}

With careful initiation and titration, opioids were a helpful and acceptable intervention for refractory dyspnea in patients with advanced COPD. Benefits outweighed risks for many patients, and benefits were sustained over several months. These findings should increase confidence in opioid prescribing in accordance with recent recommendations and practice guidelines from the American Thoracic Society, ${ }^{4}$ the American College of Chest Physicians ${ }^{28}$ and the Canadian Thoracic Society. ${ }^{11}$

\section{References}

1. Mannino DM, Buist AS. Global burden of COPD: risk factors, prevalence, and future trends. Lancet 2007;370:765-73.

2. Gershon AS, Wang C, Wilton AS, et al. Trends in chronic obstructive pulmonary disease prevalence, incidence, and mortality in Ontario, Canada, 1996 to 2007: a population-based study. Arch Intern Med 2010;170:560-5.

3. Elkington $\mathrm{H}$, White $\mathrm{P}$, Addington-Hall J, et al. The healthcare needs of chronic obstructive pulmonary disease patients in the last year of life. Palliat Med 2005; 19:485-91.

4. Mularski RA, Reinke LF, Carrieri-Kohlman V, et al. An official ATS workshop report: assessment and palliative management of dyspnea crisis. Am 7 Respir Crit Care Med 2012. In press.

5. Light RW, Muro JR, Sato RI, et al. Effects of oral morphine on breathlessness and exercise tolerance in patients with chronic obstructive pulmonary disease. Am Rev Respir Dis 1989;139:126-33.

6. Jennings AL, Davies AN, Higgins JP, et al. A systematic review of the use of opioids in the management of dyspnoea. Thorax. 2002;57:939-44.

7. Mahler DA, Murray JA, Waterman LA, et al. Endogenous opioids modify dyspnoea during treadmill exercise in patients with COPD. Eur Respir 7 2009;33: 771-7.

8. Jensen D, Alsuhail A, Viola R, et al. Inhaled fentanyl citrate improves exercise endurance during high-intensity constant work rate cycle exercise in chronic obstructive pulmonary disease. $\mathcal{F}$ Pain Symptom Manage 2012;43:706-19.

9. Abernethy AP, Currow DC, Frith P, et al. Randomised, double blind, placebo controlled crossover trial of sustained release morphine for the management of refractory dyspnoea. $B M 7$ 2003;327:523-8.

10. Currow DC, McDonald C, Oaten S, et al. Once-daily opioids for chronic dyspnea: a dose increment and pharmacovigilance study. 7 Pain Symptom Manage. 2011;42:388-99.

11. Marciniuk DD, Goodridge D, Hernandez P, et al.; Canadian Thoracic Society COPD Committee Dyspnea Expert Working Group. Managing dyspnea in patients with advanced chronic obstructive pulmonary disease: A Canadian Thoracic Society clinical practice guideline. Can Respir f 2011;18:69-78.

12. Rocker G, Young J, Donahue M, et al. Perspectives of patients, family care- 
givers and physicians about the use of opioids for refractory dyspnea in advanced chronic obstructive pulmonary disease. CMA7 2012;184:E497-504.

13. Young J, Donahue M, Simpson AC, et al. Using opioids to treat dyspnea in advanced COPD: attitudes and experiences of family physicians and respiratory therapists. Can Fam Physician 2012;58:e401-7.

14. O'Donnell DE, Hernandez P, Kaplan A, et al. Canadian Thoracic Society recommendations for management of chronic obstructive pulmonary disease -2008 update - highlights for primary care. Can Respir $72008 ; 15$ (Suppl A):1A-8A.

15. Rocker G, Horton R, Currow D, et al. Palliation of dyspnoea in advanced COPD: revisiting a role for opioids. Thorax 2009;64:910-5.

16. Anderson F, Downing GM, Hill J, et al. Palliative performance scale (PPS): a new tool. 7 Palliat Care 1996;12:5-11.

17. Puhan MA, Guyatt GH, Goldstein R, et al. Relative responsiveness of the Chronic Respiratory Questionnaire, St. Georges Respiratory Questionnaire and four other health-related quality of life instruments for patients with chronic lung disease. Respir Med 2007;101:308-16.

18. Cohen SR, Mount BM, Strobel MG, et al. The McGill Quality of Life Questionnaire: a measure of quality of life appropriate for people with advanced disease. A preliminary study of validity and acceptability. Palliat Med 1995;9:207-19.

19. Bausewein C, Farquhar M, Booth S, et al. Measurement of breathlessness in advanced disease: a systematic review. Respir Med 2007;101:399-410.

20. Dowson C, Laing R, Barraclough R, et al. The use of the Hospital Anxiety and Depression Scale (HADS) in patients with chronic obstructive pulmonary disease: a pilot study. $N Z$ Med $72001 ; 114: 447-9$.

21. Smith HS. The Numerical Opioid Side Effect (NOSE). Assessment tool. 7 Cancer Pain of Symptom Palliation 2006;1:3-6.

22. Thorne S, Con A, McGuinness L, et al. Health care communication issues in multiple sclerosis: an interpretive description. Qual Health Res 2004;14:5-22.

23. Rocker GM, Dodek PM, Heyland DK. Toward optimal end-of-life care for patients with advanced chronic obstructive pulmonary disease: Insights from a multicentre study. Can Respir 7 2008;15:249-54.

24. Schunemann HJ, Puhan M, Goldstein R, et al. Measurement properties and interpretability of the Chronic respiratory disease questionnaire (CRQ). COPD 2005;2:81-9.

25. Johnson MJ, Abernethy AP, Currow DC. Gaps in the evidence base of opioids for refractory breathlessness. A future work plan? Z Pain Symptom Manage 2012; 43:614-24.

26. Poole PJ, Veale AG, Black PN. The effect of sustained-release morphine on breathlessness and quality of life in severe chronic obstructive pulmonary disease. Am 7 Respir Crit Care Med 1998;157:1877-80.

27. Rocker G. Palliation of dyspnea. Chron Respir Dis 2012;9:49-50.

28. Mahler DA, Selecky PA, Harrod CG, et al. American College of Chest Physicians consensus statement on the management of dyspnea in patients with advanced lung or heart disease. Chest 2010;137:674-91.

Competing interests: Graeme Rocker has received support for initiating a COPD outreach program (directed to and managed by Capital District Health Authority) from GlaxoSmithKline and occasional honoraria for sponsored continuing medical education presentations from GlaxoSmithKline, Merck and Pfizer. Paul Hernandez has participated on medical advisory boards for pharmaceutical companies, as a researcher on industry-funded clinical trials, in the development of material or as a speaker for industry-funded continuing medical education for the following companies: Actelion, AstraZeneca, Boehringer Ingelheim, CSL Behring, Eli Lilly, GlaxoSmithKline, Grifols, Merck, Novartis, Pfizer and Takeda. Darcy Marciniuk has undertaken consulting or participated on advisory boards for the Canadian Lung Association, Health Canada, the Public Health Agency of Canada and the Saskatoon Health Region. He has received research support (directed to and managed by the University of Saskatchewan) from AstraZeneca, Boehringer Ingelheim, the Canadian Institute of Health Research, GlaxoSmithKline, Forest Research, the Lung Association of Saskatchewan, Novartis, Pfizer, the Saskatchewan Health Research Foundation, the Saskatchewan Ministry of Health and Schering-Plough. He holds fiduciary positions with the American College of Chest Physicians, the Chest Foundation and the Lung Association of Saskatchewan and is an employee of the University of Saskatchewan. No competing interests declared by Catherine Simpson, Joanne Young, Robert Horton, Tasnim Sinuff, Jillian Demmons or Margaret Donahue.

Affiliations: From the Division of Respirology (Rocker, Simpson, Young, Demmos, Donahue, Hernandez) QEII Health Sciences Centre, Halifax, NS; the Division of Palliative Medicine (Rocker, Horton), QEII Health Sciences Centre, Halifax, NS; the Faculty of Medicine (Rocker, Horton, Hernandez), Dalhousie University, Halifax, NS; the Department of Critical Care and Division of Respirology (Sinuff), Sunnybrook Health Sciences Centre and Sunnybrook Research Institute, Interdepartmental Division of Critical Care, University of Toronto, Toronto, Ont; and the Division of Respirology (Marciniuk), Critical Care and Sleep Medicine, Department of Medicine, University of Saskatchewan, Saskatoon, Sask.

Contributors: Graeme Rocker, Robert Horton, Tasnim Sinuff, Paul Hernandez and Darcy Marciniuk contributed to the conception and design of the study. Catherine Simpson, Joanne Young, Jillian Demmons and Margaret Donahue participated in acquiring the study data. Qualitative analysis was performed by Catherine Simpson and Margaret Donahue. All of the authors contributed to the interpretation of the data. Graeme Rocker was responsible for drafting the manuscript, and all of the authors provided critical review of drafts for important intellectual content and approved the final version submitted for publication.

Funding: This study was funded by the Canadian Institutes of Health Research (CIHR, Institute of Health Services and Policy Research, grant no. IHP 94532), the Nova Scotia Regional Partnerships Program, and the Health Promotion and Research Fund (Tier II Operating Grant) at Horizon Health Network in Saint John, NB.

Acknowledgements: The authors thank Dr. Gordon Guyatt for his invaluable insights and contributions to a successful CIHR application. The authors thank their colleagues at each study site (Dr. Chris O'Brien, Dr. Jennifer Hall and Dr. Julia Wildish in Saint John, NB; Donna Goodridge RN PhD and Tracy Dessouki RN in Saskatoon, Sask.) who assisted in the ethics approval process, recruitment of participants and medical management of the study participants. The authors also acknowledge the expertise of Shirley Wheaton, whose meticulous transcription of the interview audio files was essential to their analysis. They thank Chris Theriault and Kara Thompson, Dalhousie University Department of Medicine Research Methods Unit, and Dr. Bryan Chung, Dalhousie University Department of Surgery, for database management and statistical support. Finally, they sincerely thank the patients who participated in the study and willingly contributed their experience via study interviews and completion of questionnaires.

Supplemental information: For reviewer comments and the original submission of this manuscript, please see www.cmajopen.ca/content/1/1 /E27/suppl/DC1 